\title{
Performance evaluation of duty cycle balancing in power electronics enhanced battery packs compared to conventional energy redistribution balancing
}

\author{
Efstratios Chatzinikolaou, Student Member, IEEE and Daniel J. Rogers, Member, IEEE
}

\begin{abstract}
This paper presents a method for evaluating the performance of duty cycle balancing schemes and conventional energy redistribution active balancing schemes using a common linear programming framework. The framework is used to calculate the maximum usable capacity of a battery pack composed of cells of varying capacity coupled to a balancing circuit of a specified type and size. In the duty cycle balancing case the effect of cell redundancy for packs with $\mathrm{DC}$ and $\mathrm{AC}$ outputs is explored. In the energy redistribution case, the balancing performance of different circuit topologies with varying ratings is evaluated. An experimental validation of the numerical prediction for the duty cycle balancing method is conducted for a pack of twelve cells, where the duty cycle of each cell is controlled using a full-bridge circuit. In all cases the numerical and experimental results show an agreement in usable capacity to within $1 \%$. The experimental results indicate that for a duty-cycle balanced pack constructed from cells with an extreme capacity range (where variation between cells is as large as the average cell capacity), the inclusion of two redundant cells in a 12 cell pack enables the extraction of $95 \%$ more capacity than in the case of no redundancy.
\end{abstract}

Index Terms - Active balancing, battery equalisation, linear programming, lithium-ion batteries

\section{INTRODUCTION}

$I^{1}$ $\mathrm{N}$ battery packs, cells are connected in series and in parallel in order to achieve the required voltage and capacity ratings [1]. Differences in cell capacity are observed even between normally identical cells due to variations in the manufacturing process [2]. These initial differences generally increase as the pack is used due to varying operational conditions, for example due to small pack temperature gradients driving nonuniform cell ageing, even when care is taken to operate the cells under similar conditions. The useable capacity of a battery pack that contains series-connected cells is limited by the cell with the lowest capacity unless a balancing circuit is included. Cell balancing can be either passive or active [3]. In packs where passive balancing is implemented only the

Manuscript received May 18, 2017

This work was supported in part by the UK Engineering and Physical Sciences Research Council under grant EP/K002252/1.

E. Chatzinikolaou and D. J. Rogers are with the Energy and Power Group, Department of Engineering Science, University of Oxford, Oxford, U.K. (e-mails: efstratios.chatzinikolaou@worc.ox.ac.uk, dan.rogers@eng.ox.ac.uk). minimum cell capacity can be recovered on discharge (assuming cells cannot be bypassed) because once the cell with the lowest capacity reaches the cut-off voltage limit, discharge must be terminated. Passive balancing is performed by dissipating energy from the most charged cells through their respective shunt resistors to equalise cell state-of-charge (SoC). In practice, passive balancing schemes offer a relatively small balancing capability compared to active schemes because they inherently must dissipate energy as heat and this is wasteful and a challenge to deal with, especially in space-constrained applications. In contrast, active balancing methods are not dissipative but rather aim to individually control the rate of cell charging and discharging so that all cells have an equal $\mathrm{SoC}$ at all times during operation. Active balancing circuits are circuits that contain actively controlled switches. Most active balancing circuits described in the literature implement Energy Redistribution Balancing (ERB), where all cells are connected in series (and so all cells conduct the main pack current at all times) and balancing is performed by introducing smaller shunt currents that transfer energy between cells. ERB circuits are often placed in one of three categories, based on their architecture [4]: the adjacent cell-to-cell (A-C2C), the direct cell-to-cell (D-C2C) and the cell-to-pack (C2P). The A-C2C (Fig.1c) includes balancing circuits such as the switched capacitor [5], the bidirectional buck-boost converter [6] and the Ćuk converter [7]. The advantages of these architectures are the simple structure, modular design and low cost. However, energy can be transferred only between adjacent cells, increasing balancing time and energy losses, especially when implemented in packs with a relatively large number of cells. On the other hand, in the D-C2C architecture (Fig.1b), energy can be transferred between any two cells regardless of their position in the string, using the appropriate switches and a storage element. However, since only two cells can be balanced simultaneously, balancing time will be lengthened for a large number of imbalanced cells. The flying capacitor [8], shared inductor [9] and quasi-resonant converter [10] are some of the circuits that correspond to this architecture. In the C2P architecture (Fig.1d), energy can be transferred between a cell and the battery pack, providing flexible balancing. Energy redistribution is achieved using distributed circuits such as multiple transformers or shared storage elements such as the multiwinding transformer with leakage inductance 

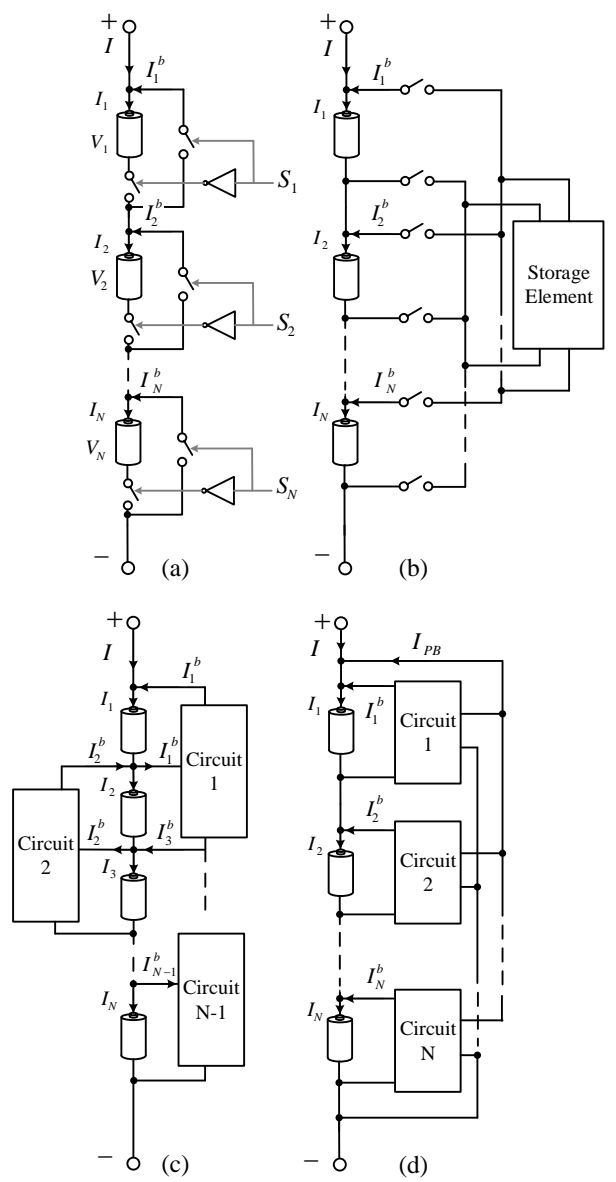

Fig. 1. a) DCB-DC circuit. b) D-C2C active balancing circuit. c) A-C2C active balancing circuit. d) $\mathrm{C} 2 \mathrm{P}$ active balancing circuit

[11]. The disadvantages of these circuits are the increased volume and cost compared to the aforementioned architectures. Apart from the inherent restrictions regarding energy redistribution between cells in each of these architectures, the ability to equalise cell SoC depends on the maximum balancing power (or balancing current) that can be transferred to/from each individual cell. The maximum balancing current of the circuits that perform active balancing typically depends on the size of the passive storage elements (inductors, capacitors, transformers) and the rating of the active switches (usually MOSFETs) used in the balancing circuit.

In order to achieve control over individual cells, 'power electronics enhanced battery packs' have been proposed for a wide range of applications [12, 13]. The power electronic switches included in the pack are rated to carry the full pack current and allow cells to be bypassed during operation in case of failure, thus enhancing the reliability of the battery, without necessarily increasing the overall cost of the system [14-16]. This is in contrast to ERB systems where all cells are in the main current path at all times. The ability to bypass cells during operation enables active balancing to be performed by controlling the duty cycle of each cell according to their relative SoC $[17,18]$ and so are referred to here as Duty Cycle Balancing (DCB) circuits. Different variations of a power electronics enhanced battery pack are presented in [16, 17, 19] but in its simplest form (Fig.1a), cells are connected in series using half-bridge (two-switch) circuits around each cell so that any individual cell can be either in series (cell current equal to the string current) or bypassed (cell current is zero). In order to enable DCB to occur, the system should be designed to include some 'redundant cells' so that the required output voltage can be reached even when some cells are bypassed. DCB can also be performed in battery pack topologies that enable direct DC to AC voltage conversion, such as in packs based on the Modular Multilevel Converter (MMC) [20, 21].

When different balancing topologies are compared in the literature, the assessment criteria (such as balancing speed, cost, circuit complexity) are often qualitatively evaluated by assigning grades such as 'excellent', 'good' and 'poor' [22]. When more-quantitative performance analysis do arise, they often focus on a single proposed balancing circuit and are therefore quite application specific [23]. Reference [24] is notable because it quantitatively describes the ability of five different balancing topologies to overcome a random initial charge imbalance by computing the balancing time and energy losses using a simple analytical model. However the main assumption in [24] is that the cells will be able to achieve balancing after a certain time, which is not always the case as will be shown later in this paper. A study of battery balancing systems using convex optimisation is presented in [25] where the objective is the minimization of pack losses, balancing circuit energy losses and pack temperature increase. In [26] a relatively complex vehicle simulation is used to compare ten different active balancing circuits as well as the influence of control variables for active cell balancing (voltage, SoC and charge capacity). This model-based approach provides a quantitative evaluation of the useable capacity when a number of cells with different capacities are used.

The aim of this paper is to compare and contrast the balancing performance of battery packs that use ERB and DCB balancing approaches. Here, 'balancing performance' is defined as the ability to effectively distribute charge among cells of the pack in proportion to their respective capacities. Accessing the total cell capacity (sum of individual cell capacities) of a pack comprising cells with different individual cell capacities is not always possible as it depends on cell redundancy for the DCB and the maximum balancing current (size of balancing circuit) in ERB circuits. As a result, the balancing performance can be quantitatively evaluated by calculating the useable capacity of the pack i.e. the percentage of the total cell capacity that can be accessed and used. It is important to note that if the inherent ability of the system to charge cells unevenly is not enough to overcome the capacity variations between cells within one cycle of operation (i.e. the time it takes for the cell with the lowest capacity to be fully charged/discharged and thus causing the pack to stop operating), balancing can never be achieved over any number of following cycles. As a result, balancing performance can always be determined within one cycle of 
operation. It is different when considering cells with equal capacities but an initial SoC imbalance. In this case, as long as a slightly different charge can be applied to each cell during each charge or discharge cycle, balancing will eventually be achieved. The balancing speed is however directly associated with the ability of the system to cope with varying capacities since this depends on the rate at which the system is able to differentially distribute charge between cells.

This paper approaches the balancing problem as a linear programming problem with the objective of maximising the useable capacity of a pack comprising cells with different capacities. The framework encompasses DCB and the ERB architectures such as A-C2C, D-C2C and C2P. This method may be particularly useful when designing, for example, a long-service life Battery Energy Storage System (BESS) where cells are expected to operate for decades and therefore may present wide variations in capacity towards end-of-life, or when designing systems using second life cells with capacities that are inherently poorly matched [27]. The aim is to provide a simple and accurate method that can be used during preliminary analysis and system design to identify key parameters (such as the maximum balancing current or cell redundancy) so that balancing circuit size or redundancy can be traded against system capacity.

\section{DUTY CYCLE BALANCING AS A LINEAR PROGRAMMING PROBLEM}

\section{A. Duty cycle balancing for DC packs (DCB-DC)}

For a power electronics enhanced battery pack using DCB, balancing can be achieved by controlling the effective duty cycle of each cell so that the cells with higher capacities are 'used more' than those with lower capacities. This can be achieved by bypassing the cells using active switches [16] as in Fig. 1 a). The average current of each cell $i$ during operation can be described by:

$$
I_{i}=I+I_{i}^{\mathrm{b}}
$$

where $I$ is the pack output current and $I_{i}^{\mathrm{b}}$ is the average balancing current of cell $i$ :

$$
I_{i}^{\mathrm{b}}=\frac{-I t_{i}^{\mathrm{b}}}{T}
$$

where $T$ is the length of operation (the length of one full charge or discharge cycle) and $t_{i}^{\mathrm{b}}$ the balancing time of cell $i$. With the duty cycle balancing a cell can either be operated normally (cell current equal to pack current) or bypassed (zero cell current). The constraints on the balancing time $t_{i}^{\mathrm{b}}$ are then:

$$
0 \leq t_{i}^{\mathrm{b}} \leq T
$$

If $t_{i}^{\mathrm{b}}$ is equal to $T$ the cell is bypassed throughout the operation and the average cell current is zero. For a balancing time equal to zero the cell is always in the current path and the average cell current is equal to the pack current $I$. In order to enable duty cycle balancing while providing the required output voltage, a number of redundant cells should be included in the pack:

$$
r=\frac{N-N_{\mathrm{a}}}{N}
$$

where $r$ is the cell redundancy ratio, $N$ is the total number of cells and $N_{\mathrm{a}}$ is the number of cells that should always be active throughout the operation of the pack to ensure the output voltage is maintained at a constant level. Due to the redundancy the average cell current is:

$$
\frac{\sum_{i=1}^{N} I_{i}}{N}=\frac{N_{\mathrm{a}} I}{N}
$$

Substituting (1) and (2) into (5):

$$
\frac{N_{\mathrm{a}} I}{N}=I-\frac{I}{T N} \sum_{i=1}^{N} t_{i}^{\mathrm{b}}
$$

The length of operation $T$ is equal to the duration of time needed to extract the useable capacity of the cells with a pack current $I$. Taking into account redundancy the operational time is given by:

$$
T=\frac{\sum_{i=1}^{N} n_{i} Q_{i}}{N_{\mathrm{a}} I}
$$

where $n_{i}$ is the useable (or accessible) fraction of the capacity $Q_{i}$ of cell $i$. This fraction must lie between 0 and 1 for all cells:

$$
0 \leq n_{i} \leq 1, \forall i \in[1 \ldots N]
$$

Substituting (7) into (6):

$$
\frac{N-N_{\mathrm{a}}}{N_{\mathrm{a}} I} \sum_{i=1}^{N} n_{i} Q_{i}=\sum_{i=1}^{N} t_{i}^{\mathrm{b}}
$$

The useable capacity of each cell is:

$$
I_{i} T=n_{i} Q_{i}
$$

Substituting (1), (2) and (7) into (10):

$$
\overbrace{\sum_{i=1}^{N} n_{i} Q_{i}}^{\begin{array}{c}
T \times \text { pack } \\
\text { current }
\end{array}}-\overbrace{I t_{i}^{\mathrm{b}}}^{\begin{array}{c}
\text { cell } i \\
\text { bypass charge }
\end{array}}=\overbrace{n_{i} Q_{i}}^{\begin{array}{c}
\text { useable capacity } \\
\text { of cell } i
\end{array}}
$$




\section{B. Duty cycle balancing for AC packs (DCB-AC)}

Battery packs that perform direct DC to AC conversion, such as the MMC topology depicted in Fig. 2, can be considered as a more complex version of DCB-DC. Using the MMC, a stepped output voltage (with a voltage step equal to the cell voltage) close to a sinusoidal voltage reference is produced by sequentially switching the converter modules. As a result of this operation, each cell experiences different average cell current due to the varying duration of time that the cells are placed in the current path (Fig. 2). It should be noted here that the low frequency current ripple that the cells experience in this case will result in higher cell losses (losses due to the cell series resistance) compared to a DC pack where the cells are operated with a smooth DC current [16].

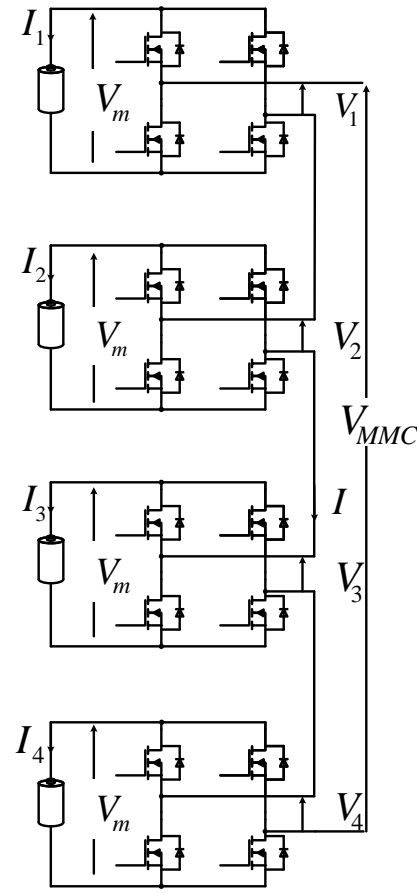

(a)
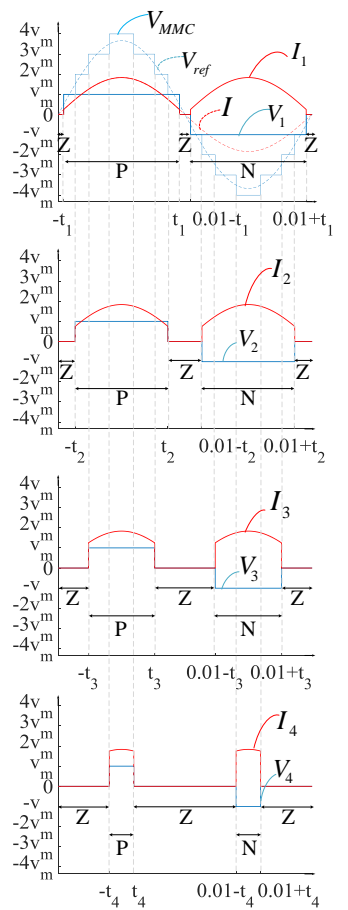

(b)

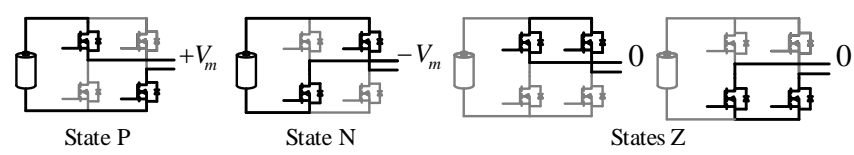

(c)

Fig. 2. Depiction of cell balancing using a 9 level DCB-AC pack based on the cascaded full-bridge MMC topology a) 9 level MMC b) current and voltage waveforms of individual cells c) sates of the full-bridge converter.

The algorithm presented in [20] uses this property of the $\mathrm{MMC}$ in order to perform cell balancing. This is achieved by using a priority list, where the cells are sorted according to their relative $\mathrm{SoC}$ in ascending or descending order, based on whether the system is charging or discharging. A voltage matching algorithm switches cells between the $\mathrm{P}, \mathrm{N}$ and $\mathrm{Z}$ states (Fig. 2) according to each cell's position in the priority list in order to produce a converter voltage close to the voltage reference. A different average cell current must therefore be assigned to each cell position $j$ [20]:

$$
I_{j}^{\mathrm{p}}=\frac{2}{\pi} \sqrt{2} I_{\mathrm{rms}} \sqrt{1-\left(\frac{j-0.5}{N_{\mathrm{a}}}\right)^{2}}
$$

where $I_{\text {rms }}$ is the output rms current of the DCB-AC pack.

Due to the different cell currents associated with each position, it is necessary to track the total duration of time that each cell spends at each of the different positions. The number of cell positions is always equal to the number of cells. Even if a number of redundant cells are used, these will be allocated to an equivalent number of 'idle positions' with zero cell current. As a result, the total time that each cell $i$ spends at the different positions $j$ as well as the total time a position $j$ is occupied by any cell $i$ should sum to the total time of operation:

$$
\begin{gathered}
\sum_{i=1}^{N} t_{i j}=\sum_{j=1}^{N} t_{i j}=\frac{\sum_{i=1}^{N} n_{i} Q_{i}}{\sum_{j=1}^{N} I_{j}^{\mathrm{p}}}, \forall i, j \in[1 \ldots N] \\
t_{i j} \geq 0, \quad \forall i, j \in[1 \ldots N]
\end{gathered}
$$

The useable capacity of each cell is in this case equal to the sum of the charge that the cell receives at the different cell positions:

$$
\sum_{j=1}^{N} I_{i j} t_{i j}=n_{i} Q_{i}, \quad \forall i \in[1 \ldots N]
$$

It should be noted here that the DCB-DC problem can be formulated as a DCB-AC problem with the position current of the first $N_{\mathrm{a}}$ positions equal to the pack current and the remaining $N-N_{\text {a }}$ positions equal to zero current. However, this results in a problem with redundant decision variables which may be simply reduced to the more compact DCB-DC formulation given previously.

\section{ENERGY REDISTRIBUTION BALANCING AS A LINEAR PROGRAMMING PROBLEM}

\section{A. Direct cell-to-cell active balancing (D-C2C)}

For a battery pack comprising series connected cells and a D-C2C balancing circuit as in Fig. 1b, the average current of each cell $i$ is given by (1). Using the shared balancing circuit, energy can be extracted or inserted to cell $i$ from any cell in the pack. The balancing current of cell $i$ is then:

$$
I_{i}^{\mathrm{b}}=\frac{b I}{T}\left(t_{i}^{\mathrm{c}}-t_{i}^{\mathrm{d}}\right)
$$

where $b$ effectively determines the 'size' of the balancing circuits: a larger value of $b$ means a larger balancing current 
can be applied; this makes the problem formulation independent of $\mathrm{C}$-rate because the maximum balancing current, and therefore the balancing circuit size, is scaled with the pack current. $t_{i}^{\mathrm{c}}$ is the time during which cell $i$ receives charge ('charging' balancing time) and $t_{i}^{\mathrm{d}}$ the time during which charge is extracted from cell $i$ ('discharging' balancing time). The balancing times $t_{i}^{\mathrm{c}}$ and $t_{i}^{\mathrm{d}}$ are constrained such that:

$$
\begin{aligned}
& 0 \leq t_{i}^{\mathrm{c}} \leq T \quad \forall i \in[1 \ldots N] \\
& 0 \leq t_{i}^{\mathrm{d}} \leq T \quad \forall i \in[1 \ldots N] \\
& t_{i}^{\mathrm{c}}+t_{i}^{\mathrm{d}} \leq T \quad \forall i \in[1 \ldots N]
\end{aligned}
$$

Since a shared storage element is used for energy exchange (e.g. in a single-inductor balancing circuit) the sum of the charging times should be less than the total time of operation because balancing can be performed only between two cells at a time:

$$
\sum_{i=1}^{N} t_{i}^{\mathrm{c}} \leq T
$$

Assuming a constant efficiency $\eta$ for the balancing circuit [24], the total power the cells receive is:

$$
\sum_{i=1}^{N} V_{i} \frac{b I t_{i}^{\mathrm{c}}}{T}=\eta \sum_{i=1}^{N} V_{i} \frac{b I t_{i}^{\mathrm{d}}}{T}
$$

Since the purpose of the balancing circuit is to ensure that the cells remain balanced or within a close SoC range during operation, the cell voltages $V_{i}$ can be assumed to be equal [24] and (21) can be simplified to:

$$
\sum_{i=1}^{N} t_{i}^{\mathrm{c}}=\eta \sum_{i=1}^{N} t_{i}^{\mathrm{d}}
$$

In a battery pack using a D-C2C balancing circuit and a pack current $I$, using (1), (10) and (16) $T$ is given by:

$$
T=\frac{\sum_{i=1}^{N} n_{i} Q_{i}-b I\left(\sum_{i=1}^{N} t_{i}^{\mathrm{c}}-\sum_{i=1}^{N} t_{i}^{\mathrm{d}}\right)}{N I}
$$

Substituting (1), (16), (22) and (23) in (10) provides a simple equality:

$$
\begin{aligned}
& T \times \text { pack current } \\
& \text { (shared by all cells) balancing circuit losses } \\
& \overbrace{\frac{\sum_{i=1}^{N} n_{i} Q_{i}}{N}}^{N}-\frac{\overbrace{b I(\eta-1) \sum_{i=1}^{N} t_{i}^{\mathrm{d}}}}{N} \\
& T \times \text { balancing useable capacity }
\end{aligned}
$$

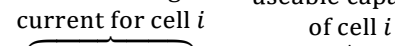

$$
\begin{aligned}
& +\overbrace{b I\left(t_{i}^{\mathrm{c}}-t_{i}^{\mathrm{d}}\right)}=\overbrace{n_{i} Q_{i}}^{\text {cell }}
\end{aligned}
$$

Finally, the time of operation $T$ should always be less than or equal to the maximum possible time of operation, that is the time needed to completely extract the charge from every cell at the average pack current: $T \leq \frac{1}{N I} \sum_{i=1}^{N} Q_{i}$. This results in the following inequality written in terms of the decision variables:

$$
\sum_{i=1}^{N}\left(1-n_{i}\right) Q_{i} \geq b I(1-\eta) \sum_{i=1}^{N} t_{i}^{\mathrm{d}}
$$

\section{B. Adjacent cell-to-cell active balancing (A-C2C)}

In the $\mathrm{A}-\mathrm{C} 2 \mathrm{C}$ architecture, each cell is restricted in exchanging energy only with its adjacent cells. According to Fig.1c, each cell $i$ (apart from the first and last cells in a string) is connected to balancing circuits $i$ and $i-1$ and the cell can either receive or extract energy from its neighbouring cells using these two balancing circuits. The average cell current in this case can also be described by (1), but the average cell balancing current is now equal to the sum of the currents provided by the adjacent balancing circuits (assuming equal cell voltages):

$$
\begin{aligned}
I_{i}^{\mathrm{b}} & =\left(\eta \frac{b I t_{i}^{\mathrm{cc}}}{T}-\frac{b I t_{i}^{\mathrm{cd}}}{T}\right)-\left(\frac{b I t_{i-1}^{\mathrm{cc}}}{T}-\eta \frac{b I t_{i-1}^{\mathrm{cd}}}{T}\right) \\
& =\frac{b I}{T}\left(\eta t_{i}^{\mathrm{cc}}-t_{i}^{\mathrm{cd}}-t_{i-1}^{\mathrm{cc}}+\eta t_{i-1}^{\mathrm{cd}}\right)
\end{aligned}
$$

where $t_{i}^{\mathrm{cc}}$ is the time during which the balancing circuit $i$ is extracting energy from cell $i+1$ to cell $i$ ('charging' time of cell $i$ through circuit $i$ ), $t_{i}^{\text {cd }}$ is the time during which the balancing circuit $i$ is extracting energy from cell $i$ to cell $i+1$ ('discharging' time of cell $i$ through circuit $i$ ) and $\eta$ the efficiency of the balancing circuit. For the charging and discharging times:

$$
\begin{aligned}
& 0 \leq t_{i}^{\mathrm{cc}} \leq T, i \in[1 . . N-1] \\
& 0 \leq t_{i}^{\mathrm{cd}} \leq T, i \in[1 \ldots N-1]
\end{aligned}
$$

The total time duration that a balancing circuit is used should be less than or equal to the time of operation:

$$
t_{i}^{\mathrm{cc}}+t_{i}^{\mathrm{cd}} \leq T, i \in[1 \ldots N-1]
$$

Using (1), (10) and (26) the balancing time for $\mathrm{A}-\mathrm{C} 2 \mathrm{C}$ is:

$$
T=\frac{\sum_{i=1}^{N} n_{i} Q_{i}+b I(1-\eta)\left(\sum_{i=1}^{N} t_{i}^{\mathrm{cc}}+\sum_{i=1}^{N} t_{i}^{\mathrm{cd}}\right)}{N I}
$$

Substituting (1), (30) and (26) in (10) provides the following equality: 


$$
\begin{aligned}
& T \times \text { pack current } \\
& \text { (shared by all cells) } \\
& \begin{array}{c}
\frac{\overbrace{\sum_{i=1}^{N} n_{i} Q_{i}}^{N}}{N}+\frac{\overbrace{b I(1-\eta)\left(\sum_{i=1}^{N} t_{i}^{\mathrm{cc}}+\sum_{i=1}^{N} t_{i}^{\mathrm{cd}}\right)}^{N}}{\begin{array}{c}
\text { useable } \\
\text { capacity } \\
\text { of cell } i \\
\text { current for cell } i
\end{array}} \\
+\overbrace{b I\left(\eta t_{i}^{\mathrm{cc}}-t_{i}^{\mathrm{cd}}-t_{i-1}^{\mathrm{cc}}+\eta t_{i-1}^{\mathrm{cd}}\right)}^{\begin{array}{c}
\text { cd } \\
n_{i} Q_{i}
\end{array}}
\end{array}
\end{aligned}
$$

Similar to (25):

$$
\sum_{i=1}^{N}\left(1-n_{i}\right) Q_{i} \geq b I(1-\eta)\left(\sum_{i=1}^{N} t_{i}^{\mathrm{cc}}+\sum_{i=1}^{N} t_{i}^{\mathrm{cd}}\right)
$$

\section{Cell-to-pack active balancing $(C 2 P)$}

In C2P topologies, energy is extracted from individual cells according to their relative $\mathrm{SoC}$ and is fed back to the pack (Fig.1d):

$$
\eta \sum_{i=1}^{N} V_{i} I_{i}^{\mathrm{b}}=N V_{i} I_{\mathrm{pb}}
$$

where $I_{\mathrm{pb}}$ is the balancing current that is returned from the balancing circuit to the pack and $\eta$ the efficiency of the balancing circuit. With the assumption of equal cell voltages:

$$
I_{\mathrm{pb}}=\eta \frac{\sum_{i=1}^{N} I_{i}^{\mathrm{b}}}{N}
$$

The average cell current is described by:

$$
I_{i}=\overbrace{I}^{\substack{\text { pack } \\
\text { current }}}-\overbrace{\frac{b I t_{i}^{\mathrm{b}}}{T}}^{\begin{array}{c}
\text { balancing current } \\
\text { extracted from cell i }
\end{array}}+\overbrace{\eta \frac{b I \sum_{i=1}^{N} t_{i}^{\mathrm{b}}}{N T}}^{\begin{array}{c}
\text { balancing current } \\
\text { returned to the pack }
\end{array}}
$$

The balancing time $t_{i}^{\mathrm{b}}$ in this case describes the total time during which energy is transferred from cell $i$ to the pack via its respective balancing circuit:

$$
0 \leq t_{i}^{\mathrm{b}} \leq T, \forall i \in[1 \ldots N]
$$

For the case where a shared storage element is used for energy exchange (such as single winding or multiwinding transformer) the sum of the cells' balancing times should be less than the total time of operation:

$$
\sum_{i=1}^{N} t_{i}^{\mathrm{b}} \leq T
$$

This constraint should not be included in cases where individual balancing circuits are used for each cell, such as in multiple transformers C2P balancing, e.g. in [28].

Using (10) and (35), the operation time for the $\mathrm{C} 2 \mathrm{P}$ is:

$$
T=\frac{\sum_{i=1}^{N} n_{i} Q_{i}+b I(1-\eta)\left(\sum_{i=1}^{N} t_{i}^{\mathrm{b}}\right)}{N I}
$$

From (1), (35) and (38) the useable capacity of each cell in a $\mathrm{C} 2 \mathrm{P}$ architecture is:

$$
\begin{aligned}
& \overbrace{\frac{\sum_{i=1}^{N} n_{i} Q_{i}}{N}}^{\begin{array}{c}
T \times \text { balancing } \\
\text { current returned } \\
\text { to pack }
\end{array}}+\overbrace{\frac{(1-\eta) b I \sum_{i=1}^{N} t_{i}^{\mathrm{b}}}{N}}^{\text {(shared by all cells) }} \\
& +\overbrace{\frac{\eta b I \sum_{i=1}^{N} t_{i}^{\mathrm{b}}}{N}}^{\text {balancing losses }}=\overbrace{\begin{array}{c}
\text { useable capacity } \\
\text { of cell } i
\end{array}}^{\begin{array}{c}
\text { of } t_{i}^{\mathrm{b}} \\
\text { current for cell } i
\end{array}}
\end{aligned}
$$

which can be simplified to:

$$
\frac{\sum_{i=1}^{N} n_{i} Q_{i}}{N}-b I t_{i}^{\mathrm{b}}+\frac{b I \sum_{i=1}^{N} t_{i}^{\mathrm{b}}}{N}=n_{i} Q_{i}
$$

Similar to (25) and (32):

$$
\sum_{i=1}^{N}\left(1-n_{i}\right) Q_{i} \geq b I(1-\eta)\left(\sum_{i=1}^{N} t_{i}^{\mathrm{b}}\right)
$$

A summary of the balancing problems (DCB-DC, DCB$\mathrm{AC}, \mathrm{D}-\mathrm{C} 2 \mathrm{C}, \mathrm{A}-\mathrm{C} 2 \mathrm{C}$ and $\mathrm{C} 2 \mathrm{P}$ ) and their formulation as linear programming problems with the objective of finding the maximum useable capacity of the pack $Q_{\mathrm{u}}^{*}$, is given in Table 1 .

\section{COMMENTS ON THE OPTIMIZATION FRAMEWORK}

The solution generated by the linear program is not necessarily unique (the uniqueness of solution can be checked using e.g. theorem 2 from [29]). If the solution is not unique then there are multiple decision variable values that result in the same maximum usable capacity and satisfy all constraints. In this case, the process of selecting one of the optimum solutions depends on the particular system under study and the aims of the system engineer. As an example, we propose secondary problem formulations for choosing a single 'best' solution: For the ERB architectures, the objective is to find the set of balancing currents (balancing times) that will result in the maximum useable capacity (as derived from the linear programming problem) but also that with the lowest overall balancing circuit power losses. Since a constant efficiency is used in this study, the balancing losses are proportional to the balancing currents and thus the balancing times. 
TABLE I

Balancing problem formulation as a linear programing problem.

\begin{tabular}{|c|c|c|c|c|c|}
\hline & DCB-DC & DCB-AC & D-C2C & A-C2C & C2P \\
\hline $\begin{array}{l}\text { Decision } \\
\text { variables }\end{array}$ & $\begin{array}{c}t_{i}^{\mathrm{b}}, n_{i} \\
\forall i \in[1, \cdots, N]\end{array}$ & $\begin{array}{c}t_{i j}, n_{i} \\
\forall i, j \in[1, \cdots, N]\end{array}$ & $\begin{array}{c}t_{i}^{\mathrm{c}}, t_{i}^{\mathrm{d}}, n_{i} \\
\forall i \in[1, \cdots, N]\end{array}$ & $\begin{array}{c}t_{i}^{\mathrm{cc}}, t_{i}^{\mathrm{cd}} \forall i \in[1, \cdots, N-1] \\
\quad n_{j} \forall j \in[1, \cdots, N-1]\end{array}$ & $t_{i}^{\mathrm{b}}, n_{i} \forall i \in[1, \cdots, N]$ \\
\hline $\begin{array}{c}\text { Objective } \\
\text { function }\end{array}$ & \multicolumn{5}{|c|}{$Q_{\mathrm{u}}^{*}=\max \left(\sum_{i=1}^{N} n_{i} Q_{i}\right)$} \\
\hline $\begin{array}{l}\text { Equality } \\
\text { constraints }\end{array}$ & $\begin{array}{l}\frac{\sum_{i=1}^{N} n_{i} Q_{i}}{N_{\mathrm{a}}}- \\
I t_{i}^{\mathrm{b}}=n_{i} Q_{i}\end{array}$ & $\begin{array}{c}\sum_{i=1}^{N} t_{i j}= \\
\sum_{j=1}^{N} t_{i j}=\frac{\sum_{i=1}^{N} n_{i} Q_{i}}{\sum_{j=1}^{N} I_{j}^{\mathrm{p}}} \\
\sum_{j=1}^{N} I_{i j} t_{i j}=n_{i} Q_{i}\end{array}$ & $\begin{array}{c}\sum_{i=1}^{N} t_{i}^{\mathrm{c}}=\eta \sum_{i=1}^{N} t_{i}^{d} \\
\frac{\sum_{i=1}^{N} n_{i} Q_{i}}{N}- \\
\frac{b I(\eta-1) \sum_{i=1}^{N} t_{i}^{\mathrm{d}}}{N}+b I\left(t_{i}^{\mathrm{c}}-\right. \\
\left.t_{i}^{\mathrm{d}}\right)=n_{i} Q_{i}\end{array}$ & $\begin{array}{c}\frac{\sum_{i=1}^{N} n_{i} Q_{i}}{N}+ \\
\frac{b I(1-\eta)\left(\sum_{i=1}^{N} t_{i}^{\mathrm{c}}+\sum_{i=1}^{N} t_{i}^{\mathrm{cd}}\right)}{N}+ \\
b I\left(\eta t_{i}^{\mathrm{cc}}-t_{i}^{\mathrm{cd}}-t_{i-1}^{\mathrm{cc}}+\eta t_{i-1}^{\mathrm{cd}}\right)= \\
n_{i} Q_{i}\end{array}$ & $\begin{array}{c}\frac{\sum_{i=1}^{N} n_{i} Q_{i}}{N}-b I t_{i}^{\mathrm{b}}+\frac{b I \sum_{i=1}^{N} t_{i}^{\mathrm{b}}}{N}= \\
n_{i} Q_{i}\end{array}$ \\
\hline $\begin{array}{l}\text { Inequality } \\
\text { constraints }\end{array}$ & $\begin{array}{l}0 \leq n_{i} \leq 1 \\
0 \leq t_{i}^{\mathrm{b}} \leq T\end{array}$ & $\begin{array}{c}0 \leq n_{i} \leq 1 \\
t_{i j} \geq 0\end{array}$ & $\begin{array}{c}0 \leq n_{i} \leq 1 \\
0 \leq t_{i}^{\mathrm{c}} \leq T \\
0 \leq t_{i}^{\mathrm{d}} \leq T \\
t_{i}^{\mathrm{c}}-t_{i}^{\mathrm{d}} \leq T \\
\sum_{i=1}^{N} t_{i}^{\mathrm{c}} \leq T \\
\sum_{i=1}^{N}\left(1-n_{i}\right) Q_{i} \geq \\
-b I(\eta-1) \sum_{i=1}^{N} t_{i}^{\mathrm{d}}\end{array}$ & $\begin{array}{c}0 \leq n_{i} \leq 1 \\
0 \leq t_{i}^{\mathrm{cc}} \leq T \\
0 \leq t_{i}^{\mathrm{cd}} \leq T \\
t_{i}^{\mathrm{cc}}-t_{i}^{\mathrm{cd}} \leq T \\
\sum_{i=1}^{N}\left(1-n_{i}\right) Q_{i} \geq b I(1- \\
\eta)\left(\sum_{i=1}^{N} t_{i}^{\mathrm{cc}}+\sum_{i=1}^{N} t_{i}^{\mathrm{cd}}\right)\end{array}$ & $\begin{array}{c}0 \leq n_{i} \leq 1 \\
0 \leq t_{i}^{\mathrm{b}} \leq T \\
\sum_{i=1}^{N} t_{i}^{\mathrm{b}} \leq T \\
\text { (shared storage element) } \\
\sum_{i=1}^{N}\left(1-n_{i}\right) Q_{i} \geq b I(1- \\
\eta)\left(\sum_{i=1}^{N} t_{i}^{\mathrm{b}}\right)\end{array}$ \\
\hline
\end{tabular}

The objective function for the $\mathrm{D}-\mathrm{C} 2 \mathrm{C}$ in that case is:

$$
\min \left(-b I\left(\sum_{i=1}^{N} t_{i}^{\mathrm{c}}-\sum_{i=1}^{N} t_{i}^{\mathrm{d}}\right)\right)
$$

For the A-C2C:

$$
\min \left(b I(1-\eta)\left(\sum_{i=1}^{N} t_{i}^{\mathrm{cc}}+\sum_{i=1}^{N} t_{i}^{\mathrm{cd}}\right)\right)
$$

And for the C2P:

$$
\min \left(b I(1-\eta)\left(\sum_{i=1}^{N} t_{i}^{\mathrm{b}}\right)\right)
$$

The equality and inequality constraints of the linear programming problem continue to apply, but now the operational time is set equal to the time required to extract the maximum useable capacity $Q_{\mathrm{u}}^{*}$, as produced from the solution of the linear programming problem:

$$
T^{*}=\frac{Q_{\mathrm{u}}^{*}}{\sum_{i=1}^{N} I_{i}}
$$

An additional equality constraint that is derived from the solution of the linear programming problem also applies:

$$
\sum_{i=1}^{N} n_{i} Q_{i}=Q_{\mathrm{u}}^{*}
$$

For the DCB-DC and DCB-AC, since a fixed number of cells are always operating, total cell losses will be constant (assuming no variation in internal cell resistances between cells). However, the optimum set of balancing times that result to the maximum useable capacity may be considered to be the one where the balancing times of each cell are as close as possible to the average balancing time (as calculated from the linear programming problem), so that losses are equally distributed among cells. This can be expressed as a convex quadratic programming problem with the following objective function for the DCB-DC (using 9):

$$
\min \left(\sum_{i=1}^{N}\left(\frac{\left(N-N_{\mathrm{a}}\right) T^{*}}{N}-t_{i}^{\mathrm{b}}\right)^{2}\right)
$$

Similarly for the DCB-AC using (13):

$$
\min \left(\sum_{j=1}^{N} \sum_{i=1}^{N}\left(\frac{T^{*}}{N}-t_{i j}\right)^{2}\right)
$$

In both cases, the equality and inequality constraints used in the respective linear programming problems should be used, with the inclusion of (45) and (46).

\section{NUMERICAL RESULTS AND DISCUSSION}

The balancing performance of a pack comprising twenty 
cells connected in series is evaluated using the different balancing approaches. Cell capacities are evenly distributed with a mean capacity of $1 \mathrm{Ah}$. The range of cell capacities (the difference between maximum and minimum cell capacities) varies between 0 and $1.6 \mathrm{Ah}$. The output pack current is $1 \mathrm{~A}$ in all cases. The useable capacity of the pack is calculated by solving the linear programming problem as formulated in Table 1, for different levels of cell redundancy (0-50\% redundancy ratio) for the DCB-DC and DCB-AC cases and for different values of the maximum balancing current $(10 \%-100 \%$ of the output pack current) in the D-C2C, $\mathrm{A}-\mathrm{C} 2 \mathrm{C}$ and $\mathrm{C} 2 \mathrm{P}$ cases. The MATLAB linprog function (default settings) is used in all cases and, as an example, exhibits a computation time of approximately $100 \mathrm{~ms}$ for a 20 cell system using a standard desktop PC when solving the DCB-AC problem.

From Fig. 3 it is clear that the maximum useable capacity is a function of the cell capacity distribution and the maximum balancing current (ERB architectures) or cell redundancy (DCB-DC/AC). For a wider cell capacity distribution, a higher balancing current or a higher redundancy ratio is required to achieve full utilisation. The DCB-AC system can achieve balancing even with no redundant cells, due to the different currents that the cells can experience based on their switching position (Fig.2). This is contrast to the DCB-DC case where cell redundancy is required to achieve balancing (if there is no redundancy all cell currents are the same all the time).

According to Fig. 3b), under the worst case capacity distribution (i.e. cell capacities spread in the range 0.2 to 1.8 $\mathrm{Ah}$ ), the useable capacity in the DCB-AC case is approximately $60 \%$ of the total capacity, whereas in the other cases, without balancing (i.e. zero redundancy in DCB-DC and zero balancing current in the ERB cases) it is limited by the lowest capacity cell to just $20 \%$. For the same extreme case, full utilisation requires $30 \%$ redundancy ratio for the DCB-AC whereas a DCB-DC system would require $45 \%$ redundancy (Fig. 3a). The D-C2C and the C2P ERB circuits using a shared storage element and the A-C2C ERB circuit with cells sorted based on their capacities present a similar (but not identical) balancing performance according to Fig.3. This is due to the limitations in energy redistribution between cells i.e. in the A-C2C balancing can be performed only between neighbouring cells so when the cells with the maximum capacity difference are placed in the opposite ends of the string, transferring energy from the lowest capacity cell to the highest capacity cells means that the intermediate balancing circuits are effectively buffering this energy thus limiting the balancing performance of the intermediate cells in the string. Similarly, when a shared storage element is used, only two cells can be balanced at a time while the rest are operated normally. When distributed balancing circuits are used to perform $\mathrm{C} 2 \mathrm{P}$ balancing performance is significantly enhanced (Fig.3c) since more than two cells can take part in the balancing process concurrently. In Fig.3e, the cells are placed in the A-C2C pack in a random order and as a result balancing performance is enhanced since the balancing circuits can now generally be used more effectively to redistribute energy between cells rather than being forced to buffer energy from the one end of the string to the other (the non-smooth graph is due to different random order being used for each data point).

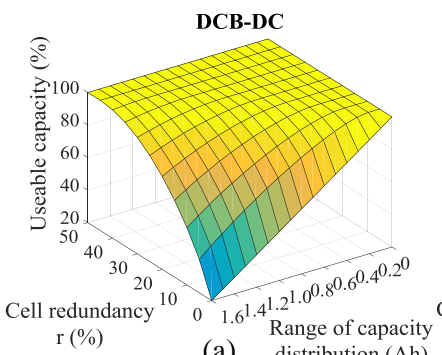

(a) distribution (Ah)

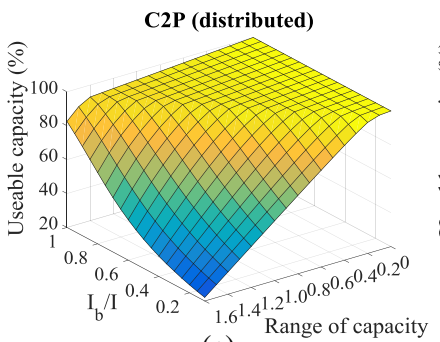

(c) distribution (Ah)

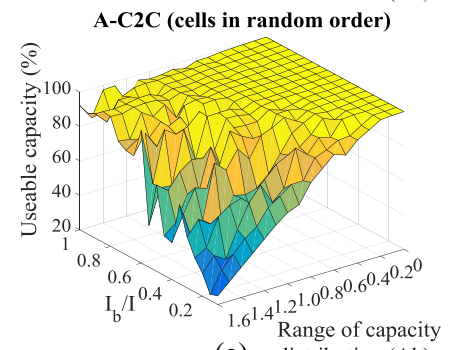

(e) distribution (Ah)

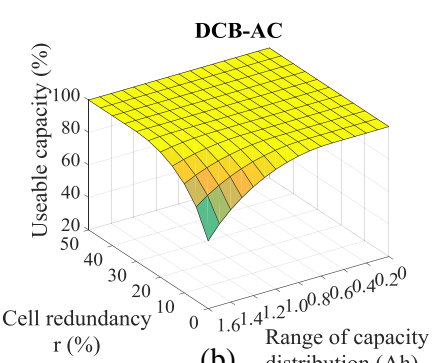

(b) distribution (Ah)

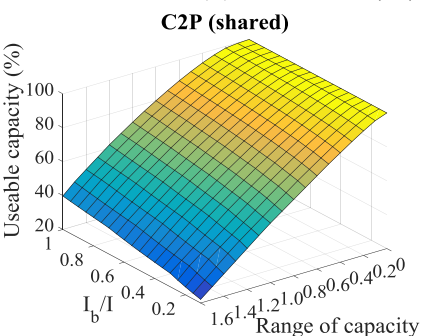

(d) distribution (Ah)

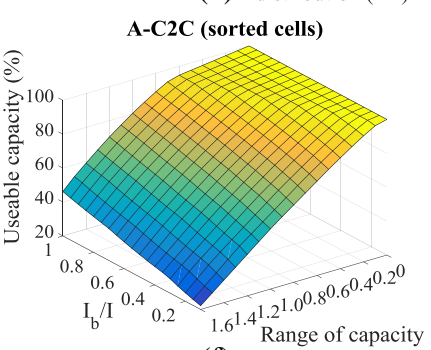

(f) Range of capacity

(f) distribution (Ah)

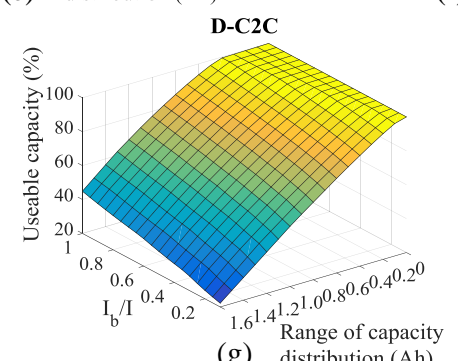

(g) distribution (Ah)

Fig. 3. Useable pack capacity of a pack of 20 cells implementing a) DCB$\mathrm{DC}$ and b) DCB-AC for different values of cell redundancy, c) C2P using distributed balancing circuits, d) $\mathrm{C} 2 \mathrm{P}$ using a shared storage element, e) A$\mathrm{C} 2 \mathrm{C}$ (with cells placed randomly in the pack in a different order for each data point, hence the non-smooth appearance) f) A-C2C (with cells sorted based on their individual capacities) and g) D-C2C for different values of maximum balancing current and $\eta=0.9$.

Some regions of Fig. 3 indicate $100 \%$ usable capacity. It is important to note that usable capacity should not be interpreted as energy efficiency, instead it is the ability of the system to extract charge from the cells: A figure of $100 \%$ indicates all cells will simultaneously reach $0 \%$ SoC at the end of a discharge cycle and $100 \%$ SoC at the end of a charge cycle. Power losses occurring in the DCB circuits (due to e.g. MOSFET on-resistance) do not impact this measure but will inevitably reduce the overall energy efficiency of the system. 
In contrast, the efficiencies of the ERB circuits do impact this measure and so are included in the analysis.
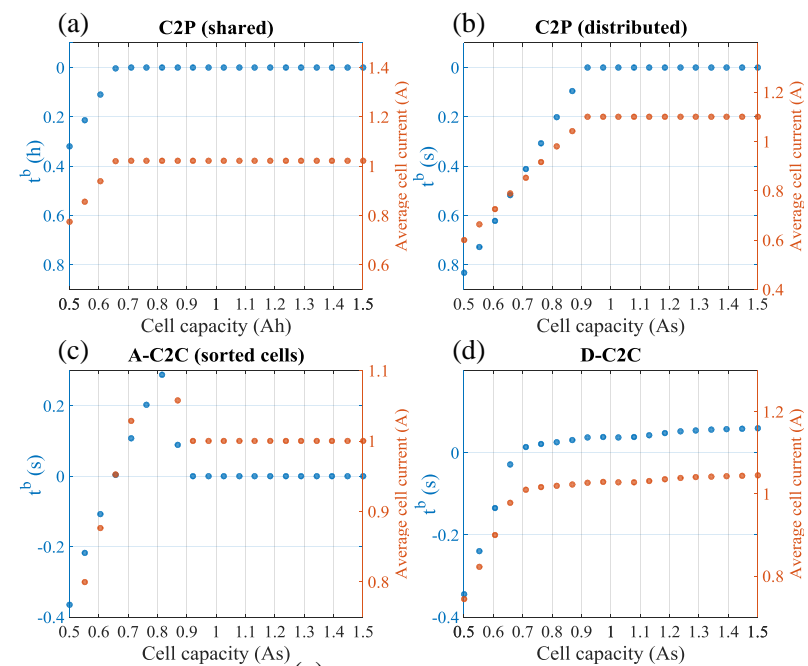

(d)

D-C2C
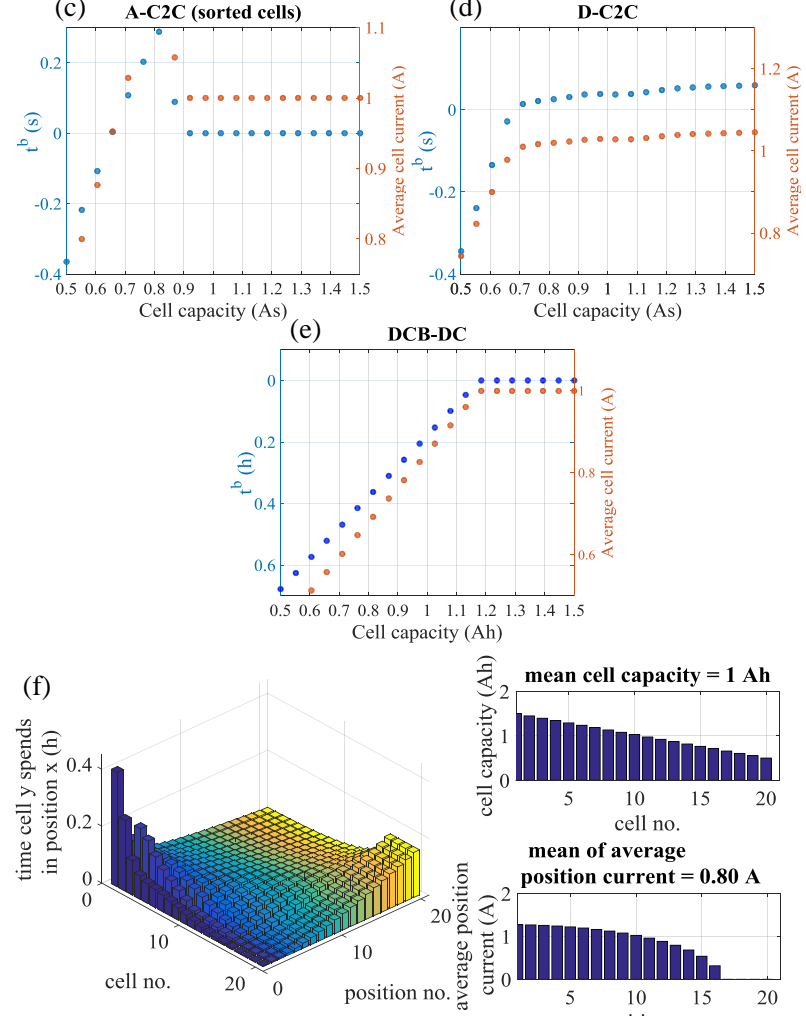

mean of average
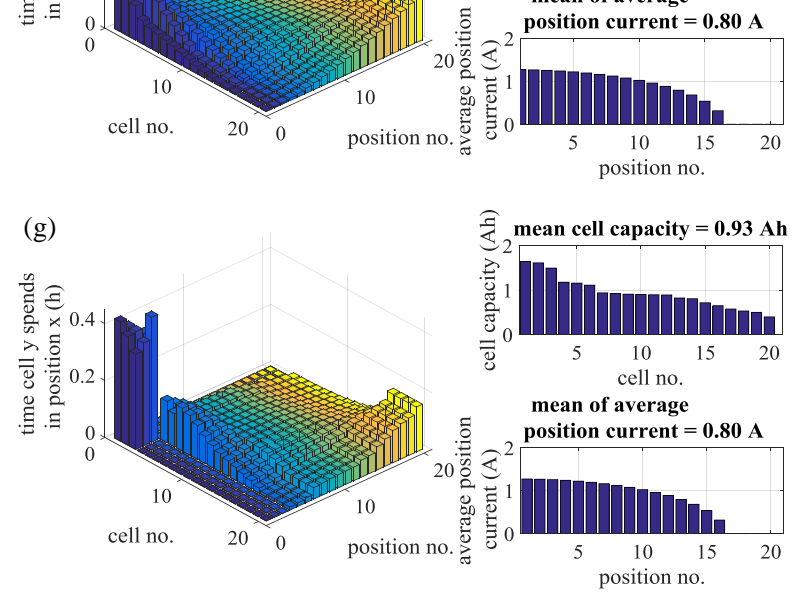

Fig. 4. a) Cell balancing time and average cell current of a pack using $\mathrm{C} 2 \mathrm{P}$ with a shared storage element b) Cell balancing time and average cell current of a pack using $\mathrm{C} 2 \mathrm{P}$ with distributed balancing circuits c) Cell balancing time and average cell current of a pack using $\mathrm{A}-\mathrm{C} 2 \mathrm{C}\left(t_{i}^{\mathrm{b}}=t_{i}^{\mathrm{cc}}-t_{i}^{\mathrm{dc}}-t_{i-1}^{\mathrm{cc}}+\right.$ $\left.t_{i-1}^{\mathrm{dc}}\right)$ with cells sorted based on their capacities d) Cell balancing time and average cell current of a pack using D-C2C (note that $I_{i}=\frac{n_{i} Q_{i}}{T}, t_{i}^{\mathrm{b}}=t_{i}^{\mathrm{c}}-$ $\left.t_{i}^{\mathrm{d}}\right)$ e) Cell balancing time and average cell current of a DCB-DC pack (note that $\left.I_{i}=I-\frac{t_{i}^{\mathrm{b}} I}{T}\right)$ f) Amount of time that each cell spends in the different positions of the DCB-AC pack (cell capacities evenly distributed) g) Amount of time that each cell spends in the different positions of DCB-AC pack (cell capacities produced using normal random number generator with $\mu=1$ and $\sigma=0.4)$.
The balancing times and average cell currents for 20 cells with cell capacities evenly spread in the range 0.5 to $1.5 \mathrm{Ah}$ are presented in Fig. 4 for the active balancing schemes ( $b=0.5, \eta=0.9$ ). In Fig.4a, C2P balancing is performed using a shared storage element, with only three cells (with the lowest capacities) providing energy to the pack $\left(t^{\mathrm{b}} \neq 0\right)$. In contrast, when distributed circuits are used in $\mathrm{C} 2 \mathrm{P}$ balancing, performance is enhanced since more cells contribute to balancing as can be seen from Fig.4b, where energy is transferred to the pack from eight different cells $\left(t^{\mathrm{b}} \neq 0\right)$. In the A-C2C (Fig.4c) the cells are sorted based on their capacity in order to observe the restrictions in energy transfer. In this case energy from the three cells with the lowest capacity is transferred (resulting in negative balancing times since $t_{i}^{\mathrm{cc}}+t_{i-1}^{\mathrm{dc}}<-t_{i}^{\mathrm{dc}}-t_{i-1}^{\mathrm{cc}}$ ) to the next four cells in the pack (for which the balancing times are positive as $t_{i}^{\mathrm{cc}}+$ $t_{i-1}^{\mathrm{dc}}>-t_{i}^{\mathrm{dc}}-t_{i-1}^{\mathrm{cc}}$ ). In the D-C2C (Fig.4d), the four cells with the lowest capacities have a negative balancing time $\left(t_{i}^{\mathrm{b}}=t_{i}^{\mathrm{c}}-t_{i}^{\mathrm{d}}\right)$, indicating that energy is extracted from these cells $\left(t_{i}^{\mathrm{c}}<t_{i}^{\mathrm{d}}\right)$, resulting in lower average cell currents compared to cells with higher capacities that experience an additional charge from their balancing currents $\left(t_{i}^{\mathrm{c}}>t_{i}^{\mathrm{d}}\right)$.

When a DCB-DC scheme is implemented, the balancing time is non zero for the cells with the lowest capacities, indicating that these cells are bypassed during operation for different amounts of time according to their respective capacities (Fig. 4e). Seven of the cells with the highest capacities are online during the entire time the pack operates ( $t^{\mathrm{b}}$ is zero) and thus their average current is equal to the pack output current.

The average time a cell spends at each position is presented in Fig. 4f for the DCB-AC case. Here, $20 \%$ redundancy is assumed so the current assigned to the last four positions is zero (idle cell positions). As expected, the six cells with the highest capacities spend a significant amount of time occupying the positions closer to one i.e. the positions that result in a higher cell current. Conversely, the cells with the lowest capacities spend most of their time remaining idle or occupying the higher positions with the least cell current.

In order to demonstrate the ability of this method to quantitatively evaluate balancing performance for any cell capacity distribution, the numerical calculations for the DCBAC pack are repeated for different cell capacities. In Fig. 4e, the 20 random capacities are drawn from a normal distribution with a mean value of $1 \mathrm{Ah}$ and a standard deviation of 0.4 .

\section{EXPERIMENTAL VALIDATION OF DCB-DC AND DCB- $\mathrm{AC}$}

The balancing performance of DCB-DC and DCB-AC methods is experimentally tested using a twelve cell battery pack (Fig. 5a). Each cell is connected to a full bridge converter and the cells are connected in series (Fig. 2). The full-bridge converter enables operating the pack as a DC pack where duty cycle balancing can be performed by bypassing cells, or a DCB-AC pack where each cell is controlled 
independently in order to produce a stepped output voltage following a sinusoidal reference.

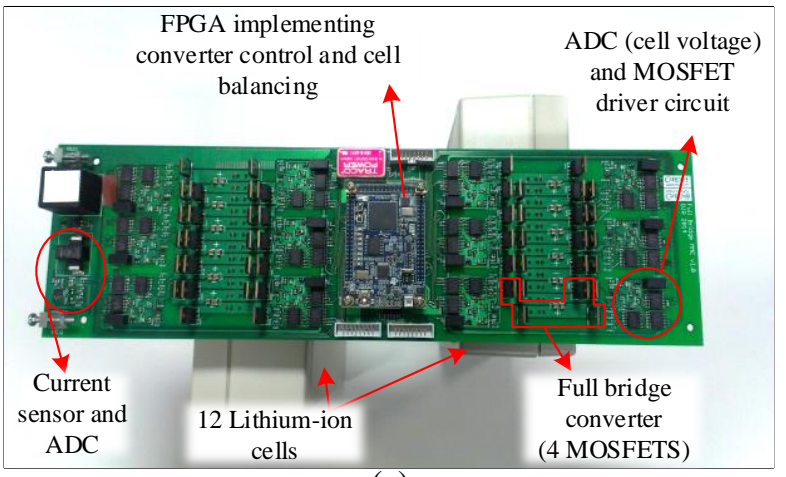

(a)

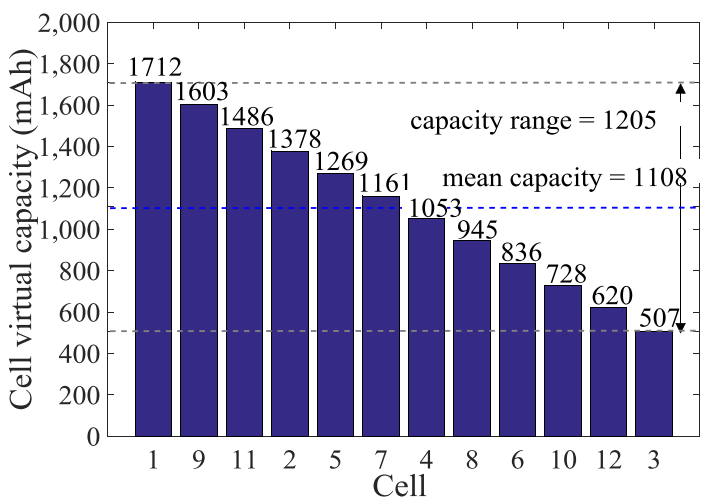

(b)

Fig. 5. a) Pack of twelve cells, where each cell is controlled individually using full bridge converter b) Virtual capacities of cells used in experiments

The balancing performance is evaluated during a discharge cycle. Balancing in both cases is performed by producing a priority list where the cells are sorted in descending order according to their SoC (a detailed description of the sorting algorithm is given in [20]). Cells whose position in the priority list is closer to 1 experience a higher discharge current than those with a position closer to 12 . Ten out of twelve cells are always on in the duty cycle balancing case, i.e. cells placed at positions 1-10 are connected in series and are discharged at the pack current. Cells at positions 11 and 12 are bypassed (zero cell current). In the DCB-AC configuration, the current assigned to each position decreases as the position number increases and cells at position 11-12 are always bypassed (i.e. correspond to redundant positions). In both configurations the switching frequency is $100 \mathrm{~Hz}$ or 0 (a cell is turned on and off twice every fundamental period, unless it is bypassed).

The cells used in these tests are lithium titanate cells with a nominal capacity of $20 \mathrm{Ah}$. In order to test the balancing performance for extreme capacity variations which were not available from the real cells, the 'virtual capacities' presented in Fig. 5b are used. A value of virtual capacity $Q_{i}^{\mathrm{v}}$ is preselected by the authors for each cell $i$, according to Fig.5b and is used during SoC estimation:

$$
\operatorname{SoC}_{i}(t)=\operatorname{SoC}_{i}^{0}+\frac{\int_{0}^{t} I_{i} d t}{Q_{i}^{\mathrm{V}}} 100
$$

where $\operatorname{SoC}_{i}^{0}$ is the initial state-of-charge set equal to $100 \%$ for all cells at the beginning of each test. Coulomb counting is performed using a single Hall Effect current sensor connected in series with the pack. The sampling rate for the pack current is $50 \mathrm{kHz}$. Operation terminates when a cell reaches zero SoC.

Since in practice cell voltages vary during operation according to the SoC, in order to ensure the redundancy ratio is kept constant (i.e. a constant number of cells are always bypassed) the following reference voltages for the pack are used:

$v_{\text {ref }}= \begin{cases}N_{\mathrm{a}} \overline{v_{\mathrm{c}}} & \text { for DCB }- \text { DC } \\ N_{\mathrm{a}} \overline{v_{\mathrm{c}}} \cos (2 \pi f t) & \text { for DCB }- \text { AC }\end{cases}$

where $\overline{v_{\mathrm{c}}}$ is the average is cell voltage of the pack and $f$ is the grid frequency. This produces a gradual decrease in output voltage as the pack discharges. In both cases, the pack load is a $12 \Omega$ resistor.

The SoC of the cells are sequentially updated every 2 seconds, so for each cell in the twelve cell pack the SoC is updated every 24 seconds. The priority list is updated every 2 seconds once a new SoC is received. The SoC update rate is restricted by the system's communication protocol. For $\mathrm{C}$ rates up to $3 \mathrm{C}$ however, the $\mathrm{SoC}$ variation of a cell in 24 seconds is less than $2 \%$, so this lag in measurement between the first and last cell does not significantly affect balancing performance in this test.

According to Table 2, the balancing performance of each balancing method is evaluated when all cells are operated $\left(\frac{N_{\mathrm{a}}}{N}=\frac{12}{12}\right)$ and when ten out of twelve cells are active $\left(\frac{N_{\mathrm{a}}}{N}=\frac{10}{12}\right)$. The useable capacity $Q_{\mathrm{u}}$ that is achieved experimentally is calculated using:

$$
Q_{\mathrm{u}}=\sum_{i=1}^{12}\left(\operatorname{SoC}_{i}^{0}-\operatorname{SoC}_{i}^{T}\right) Q_{i}^{\mathrm{v}}
$$

where $\operatorname{SoC}_{i}^{T}$ is the SoC of cell $i$ at the end of the test.

The SoC variation during operation is presented in Fig. 6. In the DCB-DC case, if no redundant cells are available, duty cycle balancing cannot be performed and so pack capacity is limited by the lowest capacity cell, in that case cell 3 . The calculated useable capacity is in that case $45 \%$ of the total pack capacity. By reducing the number of active cells to ten, duty cycle balancing can now be implemented. As a result of balancing, the useable capacity of the pack has now reached $88 \%$ of the total capacity. In order to achieve full capacity utilisation (i.e. zero SoC variation between cells) a higher redundancy ratio would be required, as can be seen from Fig. $3 \mathrm{a}$. The good agreement of the experimental and numerical 
results is also evident by the close matching of the balancing times presented in Fig. 7a). The balancing time of the cells for the experimental setup is calculated by measuring the total time that each cell spends at positions 11 and 12 (idle positions), normalised by the total operational time. As expected, the six cells with the highest capacities spend almost all of their time on, while the rest of the cells spend a considerable amount of time bypassed (occupying cell positions 11 and 12).

In the DCB-AC case, good capacity utilisation is observed even for no cell redundancy, due to the ability of the system to operate cells with different cell currents. According to the numerical results, $90 \%$ of the capacity is usable for the cell capacity distribution of Fig.5b. The capacity utilisation that is experimentally achieved is also $90 \%$ for no cell redundancy and $99 \%$ percent when ten out of twelve cells are used, agreeing with the numerical results. The difference between numerical and experimental results $(<1 \%)$ is within the experimental error (experimental error is mostly due to the accumulated error during current integration in the $\mathrm{SoC}$ estimation process).

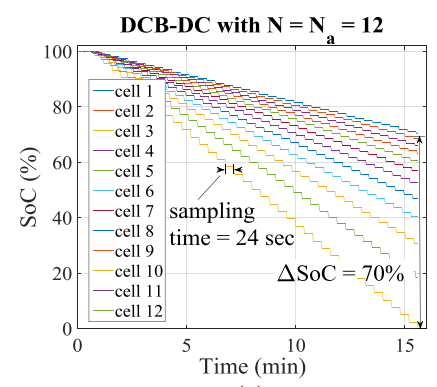

(a)

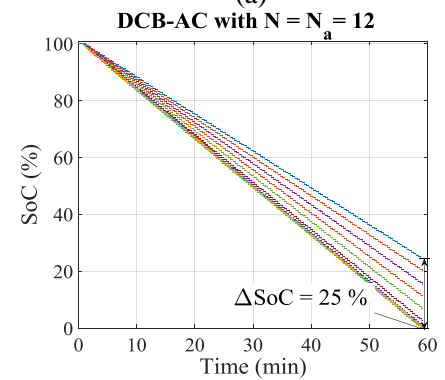

(c)

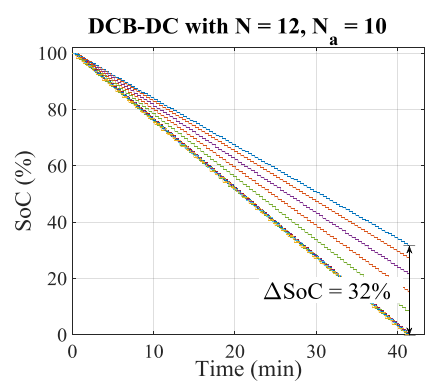

(b)

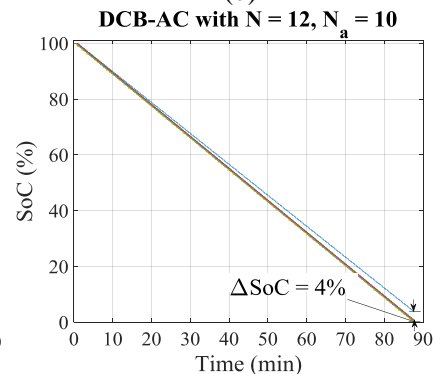

(d)
Fig. 6. SoC variation during operation for a) a DC pack with no balancing b) a DCB-DC pack with $r=\frac{1}{6}$ c) DCB-AC with no redundant cells d) DCB-AC with $r=\frac{1}{6}$.

TABLE II

Useable capacity achieved with different duty cycle balancing methods using different cell redundancy.

\begin{tabular}{|l|c|c|c|c|}
\hline $\begin{array}{c}\text { Balancing } \\
\text { Method }\end{array}$ & \multicolumn{2}{|c|}{ DCB-DC } & \multicolumn{2}{c|}{ DCB-AC } \\
\hline$N_{\mathrm{a}} / N$ & $Q_{\mathrm{u}}^{*} / \sum_{i=1}^{N} Q_{i}$ & $Q_{\mathrm{u}} / \sum_{i=1}^{N} Q_{i}$ & $Q_{\mathrm{u}}^{*} / \sum_{i=1}^{N} Q_{i}$ \\
(Numerical) & (Experimental) & $Q_{\mathrm{u}} / \sum_{i=1}^{N} Q_{i}$ \\
(Numerical) & (Experimental) \\
\hline $10 / 12$ & 0.8798 & 0.8759 & 0.9977 & 0.9912 \\
\hline $12 / 12$ & 0.4575 & 0.4536 & 0.8986 & 0.9046 \\
\hline
\end{tabular}
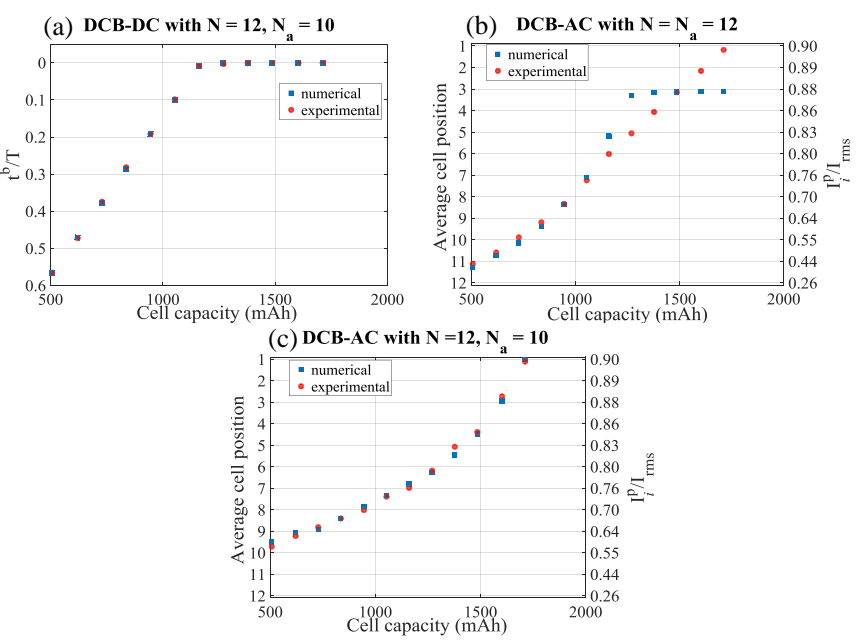

Fig. 7. Numerical and experimental results for a) balancing time in case of DCB-DC with $r=1 / 6$ b) the average cell position (and average current, note non-linear axis) versus cell capacity in case of DCB-AC with no redundancy c) the average cell position (and average current, note non-linear axis) versus cell capacity in case of DCB-AC with $r=1 / 6$.

The average position of each cell in the priority list (i.e. the effective duty cycle of each cell) is presented in Fig. 7b) and Fig. 7c). In the DCB-AC with no redundancy case, the five cells with the highest capacities all have an average cell position close to 3 based on the numerical results, whereas according to the experimental results each cell has a different average cell position with the highest capacity cells occupying positions closer to 1 (which correspond to a higher average position current, see (12)). This mismatch can be explained by considering the small variation between the average current of the neighbouring positions 1-5: for cell 5, the significant difference in average cell position (position 3 according to numerical and 5 according to experimental results) corresponds to less than 5\% difference in average current. For a larger or smaller packs, i.e. those with more or less cells (and therefore cell positions), the variation between the average current of neighbouring positions will be different but can always be calculated using (12). The linear programming tool sets the duration that each cell spends at each position by taking into account the average current associated with that position and thereby calculates constant 'position duty cycles'. On the other hand, the sorting algorithm used in the experiment places cells in different positions based only on the SoC measured from moment to moment (the algorithm does not have knowledge of the cell capacities), i.e. the resulting position duty cycles are not constant and change over the course of the discharge. It may therefore be expected that the balancing trajectories generated by the linear programming tool and experiment may differ slightly. However, due to the relatively weak dependence of position and current for position numbers less than 5, the different solutions found by the linear programming tool versus the experimental balancing algorithm produce very similar total usable capacities. This observation serves as a good example to demonstrate the value of the proposed linear programming formulation: The usable capacity figure 
provided by the optimisation $\left(Q_{\mathrm{u}}^{*}\right)$ is the theoretical maximum capacity that can be extracted from a particular pack (i.e. a pack with a specific redundancy and cell capacity distribution). The usable capacity $\left(Q_{\mathrm{u}}\right)$ delivered by any given practical on-line balancing algorithm may then be compared directly with this figure: if $Q_{\mathrm{u}}=Q_{\mathrm{u}}^{*}$ the algorithm has successfully delivered the best possible utilisation of pack capacity. If $Q_{\mathrm{u}}<Q_{\mathrm{u}}^{*}$ then this suggests there is room for improving the algorithm to achieve better capacity utilisation. By this criteria, the sorting algorithm presented here is successful because $Q_{\mathrm{u}}$ and $Q_{\mathrm{u}}^{*}$ agree to within the experimental error in all cases trialled (note that this does not necessarily imply that the algorithm used in the experiment will always extract maximum usable capacity e.g. for different cell capacities, different charge/discharge rates, different cell chemistries etc.). Although the output of the linear programming tool will always be the maximum useable capacity that can be achieved for a given balancing circuit, set of cell capacities and cell redundancy, it does not model any one particular control algorithm. The linear programming tool measures only the inherent ability of the balancing circuit to perform DCB or ERB; a practical on-line control algorithm must still be developed and tested.

\section{CONCLUSIONS}

This paper presents a method for quantitatively evaluating the balancing performance of power electronics enhanced battery packs implementing either energy redistribution balancing or duty cycle balancing, under the simplifying assumption of constant cell voltage. The balancing problem is formulated as a linear programming problem with the objective of maximising the useable capacity of a pack of cells for a given set of cell capacities. This tool can be used during the design process of the battery pack to specify the maximum balancing current or the number of redundant cells required to achieve a particular cell capacity utilisation, assuming capacity variation between cells over the lifetime of the system can be modelled. The tool can also be used to set a benchmark for any proposed balancing algorithm in the sense that it provides the maximum usable capacity for a particular set of cells, subject to a balancing current and circuit architecture (ERB) or redundancy (DCB) constraint.

The experimental results presented show that a simple DCB position-based balancing algorithm is effectively able to achieve the maximum capacity utilisation limits produced by linear programming tool. Of note is that a DCB-AC pack is able to handle relatively extreme capacity variations due to the inherent ability to operate cells under different currents, even when no cell redundancy is included.

\section{APPENDIX}

In order to check the validity of the assumptions regarding the constraints of energy redistribution in the proposed linear programming models for the ERB architectures (D-C2C, A$\mathrm{C} 2 \mathrm{C}$ and $\mathrm{C} 2 \mathrm{P}$ ), a representative model of each category is built and simulated using the PLECS [30] simulation package. In all the models a four cell battery pack is used with cells represented by constant voltage sources $(2 \mathrm{~V})$. This enables a direct comparison with the linear programming models. The SoC of the cells is calculated using (46). All cells start from zero SoC and are charged with 1 A pack current until a cell reaches $100 \%$ SoC. The details of the simulation models are given in Table 3 .

TABLE III

Details of PLECS models and comparison to linear programming results.

\begin{tabular}{|c|c|c|c|c|}
\hline & $\begin{array}{c}\text { Single } \\
\text { inductor } \\
\text { (D-C2C) }\end{array}$ & $\begin{array}{l}\text { Coupled } \\
\text { inductor } \\
(\mathrm{A}-\mathrm{C} 2 \mathrm{C})\end{array}$ & $\begin{array}{c}\text { Multi- } \\
\text { windings } \\
\text { forward } \\
\text { transform } \\
\text { er (C2P- } \\
\text { shared) }\end{array}$ & $\begin{array}{c}\text { Multiple } \\
\text { transformer } \\
\text { S } \\
\text { (C2P- } \\
\text { distributed) }\end{array}$ \\
\hline $\begin{array}{l}\text { Inductance } \\
\quad(\mathrm{mH})\end{array}$ & 1 & $\begin{array}{c}1 \\
\text { (each } \\
\text { inductor) }\end{array}$ & $\begin{array}{c}4 \\
\text { (magnetisin } \\
\mathrm{g} \\
\text { inductance } \\
\text { at each } \\
\text { primary) }\end{array}$ & $\begin{array}{c}1 \\
\text { (magnetising } \\
\text { inductance } \\
\text { at each } \\
\text { primary) }\end{array}$ \\
\hline $\begin{array}{c}\text { Maximum } \\
\text { balancing } \\
\text { current (A) }\end{array}$ & \multicolumn{4}{|c|}{0.25} \\
\hline $\begin{array}{c}\text { PWM } \\
\text { switching } \\
\text { frequency } \\
\text { (Hz) }\end{array}$ & \multicolumn{4}{|c|}{1000} \\
\hline $\begin{array}{l}\text { PWM duty } \\
\text { cycle (\%) }\end{array}$ & \multicolumn{4}{|c|}{50} \\
\hline $\begin{array}{l}\text { Mean cell } \\
\text { capacity } \\
\text { (Ah) }\end{array}$ & \multicolumn{4}{|c|}{1} \\
\hline $\begin{array}{l}\text { Capacity } \\
\text { range }(A h)\end{array}$ & \multicolumn{4}{|c|}{$0-1.6$ (step of 0.1$)$} \\
\hline $\begin{array}{c}\text { Mean Average } \\
\text { Percentage } \\
\text { Error of useabl } \\
\text { capacity } \\
\left(\frac{\sum_{i=1}^{17} 100 \frac{Q_{\mathbf{u}}^{*}(i)-Q_{\mathbf{u}}(i)}{Q_{\mathbf{u}}^{*}(i)}}{17}\right.\end{array}$ & 0.008 & 0.080 & 0.023 & 2.646 \\
\hline
\end{tabular}

The representative circuit for the $\mathrm{D}-\mathrm{C} 2 \mathrm{C}$ architecture is the single inductor circuit of [28]. At every switching cycle, the cell with the maximum SoC transfers energy to the one with the lowest $\mathrm{SoC}$ via the inductor. For the A-C2C, the coupled inductor circuit of [28] is used. In this case, balancing occurs between adjacent cells by switching the higher SoC cell across the coupled inductor, followed by the lower SoC cell. The $\mathrm{C} 2 \mathrm{P}$ with a shared storage element is validated using the multi-winding transformer in the forward structure as in [28]. Here the MOSFET of the cell with the highest SoC is switched on to discharge the cell and transfer the energy to the pack through the secondary of the multi-winding transformer. For the validation of the $\mathrm{C} 2 \mathrm{P}$ with distributed balancing circuits, the multiple transformer circuit of [28] is used. The individual transformer connected to each cell is used to transfer energy from the cells with a SoC higher than the average SoC to the whole pack.

The useable capacity achieved through simulation $\left(Q_{\mathrm{u}}\right)$ is compared to the maximum useable capacity provided by the 
linear programming tool $\left(Q_{\mathrm{u}}^{*}\right)$ and the results are presented in Table 3. In all the cases, except the $\mathrm{C} 2 \mathrm{P}$-distributed, the error between the output of the linear programming tool and the useable capacity achieved through simulation is less than $0.1 \%$. The error in the $\mathrm{C} 2 \mathrm{P}$-distributed case is attributed to the inability of the balancing algorithm used in the simulation to fully utilise the balancing capabilities of the circuit. To test this assumption, the balancing times (duty cycles) of each cell as calculated from the solution of the linear programming problem were applied to the simulation circuit (open loop control) and the maximum useable capacity was then achieved.

\section{REFERENCES}

[1] L. Lu, X. Han, J. Li, J. Hua, and M. Ouyang, "A review on the key issues for lithium-ion battery management in electric vehicles," Journal of Power Sources, vol. 226, pp. 272-288, 2013.

[2] T. Baumhöfer, M. Brühl, S. Rothgang, and D. U. Sauer, "Production caused variation in capacity aging trend and correlation to initial cell performance," Journal of Power Sources, vol. 247, pp. 332-338, 2014.

[3] J. Gallardo-Lozano, E. Romero-Cadaval, M. I. Milanes-Montero, and M. A. Guerrero-Martinez, "Battery equalization active methods," Journal of Power Sources, vol. 246, pp. 934-949, 2014.

[4] Z. Zhang, H. Gui, D.-J. Gu, Y. Yang, and X. Ren, "A hierarchical active balancing architecture for lithium-ion batteries," IEEE Trans. Power Electron., vol. 32, pp. 2757-2768, 2017.

[5] Y. Yuanmao, K. Cheng, and Y. Yeung, "Zero-current switching switched-capacitor zero-voltage-gap automatic equalization system for series battery string," IEEE transactions on power electronics, vol. 27, pp. 3234-3242, 2012.

[6] B. Dong, Y. Li, and Y. Han, "Parallel architecture for battery charge equalization," IEEE Transactions on Power Electronics, vol. 30, pp. 4906-4913, 2015.

[7] Y.-S. Lee and M.-W. Cheng, "Intelligent control battery equalization for series connected lithium-ion battery strings," IEEE Transactions on Industrial electronics, vol. 52, pp. 1297-1307, 2005.

[8] F. Baronti, G. Fantechi, R. Roncella, and R. Saletti, "High-efficiency digitally controlled charge equalizer for series-connected cells based on switching converter and super-capacitor," IEEE Transactions on Industrial Informatics, vol. 9, pp. 1139-1147, 2013.

[9] S. Yarlagadda, T. T. Hartley, and I. Husain, "A battery management system using an active charge equalization technique based on a DC/DC converter topology," IEEE Transactions on Industry Applications, vol. 49, pp. 2720-2729, 2013.

[10] Y. Shang, C. Zhang, N. Cui, and J. M. Guerrero, "A cell-to-cell battery equalizer with zero-current switching and zero-voltage gap based on quasi-resonant LC converter and boost converter," IEEE Transactions on Power Electronics, vol. 30, pp. 3731-3747, 2015.

[11]T. Anno and H. Koizumi, "Double-input bidirectional DC/DC converter using cell-voltage equalizer with flyback transformer," IEEE Transactions on Power Electronics, vol. 30, pp. 2923-2934, 2015.

[12] S. Ci, N. Lin, and D. Wu, "Reconfigurable battery techniques and systems: A survey," IEEE Access, vol. 4, pp. 1175-1189, 2016.

[13] T. Morstyn, M. Momayyezan, B. Hredzak, and V. G. Agelidis, "Distributed Control for State-of-Charge Balancing Between the Modules of a Reconfigurable Battery Energy Storage System," IEEE Trans. Power Electron., vol. 31, pp. 7986-7995, 2016.

[14] M. Liu, W. Li, C. Wang, M. P. Polis, Y. Le Wang, and J. Li, "Reliability evaluation of large scale battery energy storage systems," IEEE Trans. Smart Grid, 2017.

[15]H. Kim and K. G. Shin, "DESA: Dependable, efficient, scalable architecture for management of large-scale batteries," IEEE Trans. Ind. Informat., vol. 8, pp. 406-417, 2012.

[16]E. Chatzinikolaou and D. J. Rogers, "A Comparison of Grid-Connected Battery Energy Storage System Designs," IEEE Trans. Power Electron., vol. 32, pp. 6913-6923, 2017.

[17]D. Frost and D. Howey, "Completely decentralised active balancing battery management system," IEEE Trans. Power Electron., 2017.
[18] Y. Li and Y. Han, "A Module-Integrated Distributed Battery Energy Storage and Management System," IEEE Trans. Power Electron., vol. 31, pp. 8260-8270, 2016.

[19] A. Manenti, A. Abba, A. Merati, S. M. Savaresi, and A. Geraci, "A new BMS architecture based on cell redundancy," IEEE Trans. Ind. Electron., vol. 58, pp. 4314-4322, 2011.

[20]E. Chatzinikolaou and D. J. Rogers, "Cell SoC Balancing Using a Cascaded Full-Bridge Multilevel Converter in Battery Energy Storage Systems," IEEE Trans. Ind. Electron., vol. 63, pp. 5394-5402, 2016.

[21]M. Vasiladiotis and A. Rufer, "Analysis and control of modular multilevel converters with integrated battery energy storage," IEEE Trans. Power Electron., vol. 30, pp. 163-175, 2015.

[22]M. Daowd, N. Omar, P. Van Den Bossche, and J. Van Mierlo, "Passive and active battery balancing comparison based on MATLAB simulation," in Vehicle Power and Propulsion Conference (VPPC), 2011 IEEE, 2011, pp. 1-7.

[23]W. C. Lee, D. Drury, and P. Mellor, "Comparison of passive cell balancing and active cell balancing for automotive batteries," in Vehicle Power and Propulsion Conference (VPPC), 2011 IEEE, 2011, pp. 1-7.

[24]F. Baronti, R. Roncella, and R. Saletti, "Performance comparison of active balancing techniques for lithium-ion batteries," Journal of Power Sources, vol. 267, pp. 603-609, 2014.

[25]C. Pinto, J. V. Barreras, E. Schaltz, and R. E. Araújo, "Evaluation of Advanced Control for Li-ion Battery Balancing Systems Using Convex Optimization," IEEE Trans. Sustain. Energy, vol. 7, pp. 1703-1717, 2016.

[26] M. Caspar, T. Eiler, and S. Hohmann, "Systematic Comparison of Active Balancing: A Model-based Quantitative Analysis," IEEE Trans. Veh. Technol., 2016.

[27]C. R. Birkl, D. F. Frost, A. M. Bizeray, R. R. Richardson, and D. A. Howey, "Modular converter system for low-cost off-grid energy storage using second life li-ion batteries," in Global Humanitarian Technology Conference (GHTC), 2014 IEEE, 2014, pp. 192-199.

[28] M. Hoque, M. Hannan, A. Mohamed, and A. Ayob, "Battery charge equalization controller in electric vehicle applications: A review," Renewable and Sustainable Energy Reviews, 2016.

[29] O. L. Mangasarian, "Uniqueness of solution in linear programming," Linear algebra and its applications, vol. 25, pp. 151-162, 1979.

[30] Available: https://www.plexim.com/plecs

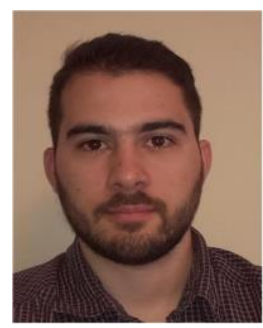

Efstratios Chatzinikolaou (S'16) received the Diploma degree in electrical and computer engineering from National Technical University of Athens, Athens, Greece, in 2013. He is currently working toward the DPhil in Engineering Science at the University of Oxford, U.K. His research interests include modular multilevel converter topologies and power electronic interfaces for battery energy storage systems.

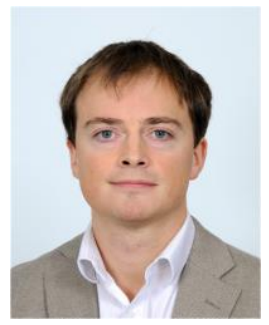

Daniel J. Rogers (M'09) received the M.Eng. and $\mathrm{Ph} . \mathrm{D}$. degrees in electrical and electronic engineering from Imperial College London, London, U.K., in 2007 and 2011 respectively. Currently, he is an Associate Professor at the University of Oxford, U.K. He conducts research in collaboration with industry and is an investigator on EPSRC and EU research projects in the areas of power electronics, HVDC and grid-scale energy storage. His research interests include the use of medium- and large-scale power electronic systems to create flexible electrical networks capable of taking advantage of a diverse range of generation technologies. 